\title{
Panorama da ginástica artística feminina brasileira de alto rendimento esportivo: progressão, realidade e necessidades
}

CDD. 20.ed. 796.41

796.48
Laurita Marconi SCHIAVON*

Roberto Rodrigues PAES**

Eliana de TOLEDO***

Silvia DEUTSCH*

\section{Resumo}

Os resultados das atletas brasileiras da Ginástica Artística feminina nos últimos 10 anos, refletidos principalmente nas competições de nível internacional, apontam para uma expressiva evolução do esporte no país. Assim, este artigo tem o propósito de apresentar dados acerca desta transformação, principalmente a partir da participação das ginastas em Jogos Olímpicos (desde 1980), e estabelecer reflexões em relação ao desenvolvimento da modalidade no país. A partir de uma pesquisa bibliográfica e documental, estes dados foram obtidos, reunidos e contextualizados com outras informações já disponíveis na literatura. Ao analisá-los foi possivel não só apontar com especificidade como se deu esta evolução, como também apresentar uma realidade deflagradora de um processo ainda imaturo de desenvolvimento do esporte no país, que não condiz em grande parte com o que é posto pela mídia (de que a modalidade está em pleno avanço e de forma estruturada).

Palavras-chave: Ginástica; Jogos Olímpicos; Esportes.

\section{Introdução}

Debruçar-se sobre o estudo da história da Ginástica tem sido um objetivo das pesquisadoras deste artigo há alguns anos, por meio dos trabalhos desenvolvidos no Grupo de Pesquisa em Ginástica da FEF/UNICAMP (ao qual pertencem) e também no âmbito da pós-graduação. Analisar estes dados históricos, obtidos em pesquisas que utilizaram os mais diversificados métodos, configura-se uma busca de reuní-los, algo incomum na área da ginástica, e também de analisá-los numa única composição acadêmica, propiciando um melhor entendimento do fenômeno estudado.

E é neste contexto que surge o presente artigo, voltado para a congruência de pesquisas históricas acerca da ginástica artística feminina (GAF) de alto rendimento e uma análise da realidade.

Assim, o propósito deste artigo é expor dados históricos, em sua maioria não apresentados pela literatura nacional nesta área, acrescentando-lhes análises e discussōes acerca do panorama da GAF brasileira.

$\mathrm{O}$ conjunto de informações desta pesquisa foi obtido por meio de pesquisas bibliográfica e documental. A pesquisa bibliográfica foi realizada em livros, teses, dissertaçóes e publicações em periódicos nacionais, levantadas nas bases de dados: SciELO, Portal CAPES (periódicos e banco de teses) e Google Acadêmico, tendo como palavras-chave: Ginástica e Ginástica Artística. Os dados da pesquisa documental foram coletados no site da Federação Internacional de Ginástica (FIG), da Confederação Brasileira de Ginástica (CBG) e das Federações Estaduais que possuem sites oficiais (BA, PR, RJ, RS e SC). Para obter as informações de Federações que não têm sites, ou daquelas que não dispunham as informaçōes requeridas nos sites, foram realizados contatos diretos com os respectivos dirigentes, sendo seis federações via email (AM, CE, DF, MA, RO, SP) e 12 federaçōes por telefone ${ }^{a}$ (AL, ES, GO, MG, MS, PA, PB, PE, RN, RR, SE e TO).

Os dados ora levantados e a sua análise potencializam e incentivam, sobremaneira, a reflexão por parte dos técnicos, pesquisadores e ginastas acerca do processo de desenvolvimento da Ginástica Artística (GA), como um campo fértil de colaboração e intervenção sobre a realidade.

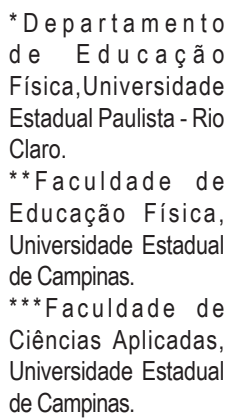




\section{Algumas cenas acerca do surgimento da ginástica artística no Brasil}

Para compreender o cenário atual da GA brasileira, os dados históricos são de extrema relevância, uma vez que revelam a forma pela qual a modalidade evoluiu ${ }^{\mathrm{b}}$ no país, e quais fatores foram decisivos para isso, o que permite analisar num recorte histórico suas rupturas e permanências até a atualidade.

Dados apontados por TESCHE ${ }^{1}$ e FIORIN ${ }^{2}$ revelam que em meados do século XIX havia grupos de ginástica dispersos nas regiōes Sul e Sudeste, como uma forma dos imigrantes alemães manterem sua identidade cultural no Brasil. Alguns destes grupos constituíram-se em Associações de Ginástica, como a Sociedade Ginástica de Joinville/SC, fundada em 1858, a SOGIPA - Sociedade de Ginástica de Porto Alegre, em 1867, e outras que se formaram no início do século $\mathrm{XX}^{3}$.

A primeira federação estadual de ginástica no Brasil surge em 1942, no Rio Grande do Sul, com a fundação da Federação Riograndense de Ginástica, para incentivar a prática da ginástica esportivizada ${ }^{3}$.

Ressalta-se neste processo, tão citado em outras publicaçōes, que a institucionalização da ginástica (associações e a primeira federação) foi iniciativa de grupos específicos de interesse, sem muita relação com um investimento esportivo por parte do poder público ou de confederaçôes esportivas. Ou seja, havia manifestações espalhadas em todo país (mais fortemente nas regiōes Sul e Sudeste) de grupos de origem alemã, que cultivavam e tornavam sistemática a prática do método alemão de ginástica, e este parece ter sido um dos mais fortes motivos para o desenvolvimento de sua estruturação como uma ginástica esportivizada (portanto, da ginástica artística), conforme sinalizam os estudos de SAGaWA ${ }^{4}$ na cidade de São Paulo. É possível também conjecturar que, de algum modo, alguns outros aspectos anteriores a esta data tenham colaborado igualmente para a divulgação e prática deste tipo de ginástica, constituindo um terreno mais fértil para sua configuração posterior como uma modalidade esportiva:

- O incentivo da prática da ginástica alemã desde 1860, especialmente nas escolas militares, principalmente devido à influência da arquiduquesa da Áustria e primeira imperatriz do Brasil, Maria Leopoldina Josefa Carolina, de Habsburgo ${ }^{5}$;

- A obrigatoriedade do ensino do método alemão de ginástica, em 1882, inicialmente nas escolas militares de todo o país, e posteriormente nas escolas da então capital da República, Rio de Janeiro ${ }^{6}$;

- Depois deste período, o ensino de outros tipos de ginástica nas escolas de todo o Brasil, de forma obrigatória ou como orientação da política pública que, de certo modo, influenciaram a manutenção da prática da ginástica em diferentes setores sociais, como clubes, associações etc ${ }^{7}$.

Após a fundação da primeira federação esportivizada de ginástica, em 1942, surge a Federação Paulista de Ginástica, em 1948 e, em 1950, a Federação Metropolitana de Ginástica do Estado do Rio de Janeiro. Essas três federações se vincularam à Confederação Brasileira de Desportos que, por sua vez, se filiou à Federação Internacional de Ginástica (FIG) em 1951 e organizou o primeiro Campeonato Brasileiro de $\mathrm{GA}^{\mathrm{c}}$, com a participação das seleções de GA masculina dos Estados do Rio Grande do Sul, de São Paulo e do Rio de Janeiro. "Em 1952, foi realizado o II Campeonato Brasileiro de GA, desta vez em Porto Alegre-RS, pela primeira vez com a participação feminina" (p.220) ${ }^{8}$.

Em 1973, com apoio da FIG, os melhores ginastas do mundo vieram para uma turnê ao Brasil, o que motivou os vários Estados brasileiros para a prática da GA, além do fato de receberem oito jogos completos de aparelhos oficiais. Após esta iniciativa, o Ministério da Educação e da Cultura (MEC) oferece o primeiro de quatro Cursos Nacionais de GA para capacitação de professores, com vistas à participação de atletas nos Jogos Escolares Brasileiros?.

Em 1978, foi criada a Confederação Brasileira de Ginástica $(\mathrm{CBG})^{3}$, e vale a reflexão acerca da pouca intervenção do poder público e da FIG para este desenvolvimento inicial da modalidade (especificamente a ginástica artística e não mais a ginástica alemã de condicionamento físico) no país. Dito de outro modo, algumas federações de ginástica se constituem e ocorrem algumas ações pontuais (como cursos, competições etc) advindas de iniciativas de grupos de interesses específicos, e não de outros órgãos que têm como missão institucional o desenvolvimento do esporte.

No mesmo ano o Brasil, pela primeira vez, participa de um Campeonato Mundial (CM) (França) com uma equipe. Nele a ginasta Lillian Carrascozza (RJ) obtém o brevê de ginasta internacional da FIG (reconhecimento para ginastas que obtivessem média acima de 9,0 pontos). Em 1980, no Rio de Janeiro, surge o projeto "Medalha de Ouro", com patrocínio do Colégio Impacto e apoio da CBG que, pela primeira vez, organiza um centro de treinamento específico e contrata técnicos soviéticos para trabalharem com as ginastas brasileiras selecionadas, com o objetivo de 
participar dos Jogos Olímpicos (JO) de 1984. "Apesar do projeto não ter vingado serviu de parâmetro para futuros projetos nacionais" (p.224) .

Sobre outros intercâmbios de técnicos, PúBLIO ${ }^{3}$ descreve que, ainda em 1969 o francês Chautemps ministrou curso pela Federação Paulista de Ginástica (FPG), que também intermediou a vinda de dois técnicos japoneses em 1970. Em 1978, com patrocínio do MEC, a CBG realizou, no Rio de Janeiro, o I Seminário para Técnicos de Desportos de Alto Nível, com professores alemães. No mesmo ano, diferentes países participaram de uma clínica de GA; e, em 1980, foi realizado um curso técnico como parte do "Programa de Treinamento para Técnicos do Desporto de Alto Nível", do convênio Brasil-Alemanha, promovido pelo $\mathrm{MEC}^{3}$.

As iniciativas e apoios da Federação Paulista de Ginástica, da CBG e do MEC resultaram, naquele momento, numa qualificação de técnicos oriundos dos melhores centros de ginástica do mundo e com conhecimento atualizado, o que certamente influenciou as geraçōes seguintes e impulsionou o cenário da GA brasileira. Estas iniciativas, somadas a outras advindas dos mais diferentes setores sociais, sem dúvida marcam a evolução da modalidade. Por meio destes fatos, conclui-se que um conjunto de elementos integrados foi fundamental para que esta evolução ocorresse, tais como: ter uma ginasta brasileira de destaque internacional, realizar cursos de capacitação para técnicos, ter o apoio de instituições particulares (no caso, um colégio) e públicas (MEC), ter uma melhor estruturação das instituiçôes federativas na área da Ginástica (FPG, CBG), dentre outros.

Ressalta-se que atualmente esse tipo de iniciativa e/ou apoio da CBG mostra-se fundamental para o desenvolvimento da GAF, assim como das outras modalidades ginásticas, e está definida como uma das competências explícitas em seu Estatuto de 2004 (reformulado em 2008). O Estatuto prevê o dever de "dirigir, difundir, promover, organizar e aperfeiçoar" 10 as sete modalidades sob sua responsabilidade: Ginástica Artística Feminina, Ginástica Artística Masculina, Ginástica Rítmica, Ginástica de Trampolim, Ginástica Acrobática, Ginástica Aeróbica Esportiva e Ginástica para todos.

De acordo com o Estatuto da $\mathrm{CBG}^{10}$ :
A abrangência da Confederação Brasileira de Ginástica está em âmbito nacional e regional em relação à ginástica escolar, universitária, de clube e entre Federações filiadas em todos os níveis, inclusive a ginástica praticada por portadores de deficiências quando a Federação Internacional permitir (p.5).

Além disso, por meio dos Comitês Técnicos de cada modalidade ${ }^{10}$, a CBG deve:

- Elaborar os Regulamentos Específicos da modalidade pertinente.

- Manifestar-se sobre o Calendário Anual da Confederação Brasileira de Ginástica.

- Instituir a Programação das Competições.

- Propor as categorias dos Campeonatos oficiais da CBG.

- Organizar Cursos e outros eventos, com o objetivo de desenvolver a Ginástica.

- Indicar entre os seus membros: Diretor de Competição e Diretor de Arbitragem de cada Evento, e Supervisor dos Cursos Internacionais e Nacionais de Arbitragem e Técnicos.

Dentre outras importantes funções do Comitê Técnico no Estatuto da $\mathrm{CBG}^{10}$ destaca-se o Artigo 40 pela sua abrangência e importância para o desenvolvimento da ginástica brasileira: "Propor instrumentos que estimulem e orientem o desenvolvimento técnico da ginástica brasileira” (p.25) ${ }^{10}$. A partir de uma análise da realidade, que será detalhada adiante, nota-se que este artigo do estatuto merece mais destaque com maior oferta e melhor qualidade destes instrumentos, para que viabilizem o desenvolvimento técnico das modalidades ginásticas no país. Neste artigo, destacamos a GAF entre as modalidades ginásticas.

Saliente-se que a CBG não está sozinha e tem o apoio das Federações Estaduais para atingir seus objetivos estatutários. É papel da CBG estabelecer algumas normativas e ações para todo o país. Contudo, as federaçōes também têm autonomia para promoverem as modalidades, por meio das mais diferentes iniciativas, com o apoio de seus associados e da própria CBG.

Em 2011, segundo dados fornecidos pelas próprias Federaçōes Estaduais, apresentados no QUADRO 1, 23 destas estavam filiadas à CBG, com suas respectivas entidades federadas. 
QUADRO 1 - Federações estaduais e suas entidades filiadas em 2011.

\begin{tabular}{|c|c|c|c|}
\hline & Federaçóes Estaduais & Entidades filiadas & Regiáo \\
\hline 1 & São Paulo & 39 & Sudeste \\
\hline 2 & Rio de Janeiro & 33 & Sudeste \\
\hline 3 & Rio Grande do Sul & 21 & Sul \\
\hline 4 & Rio Grande do Norte & 18 & Nordeste \\
\hline 5 & Minas Gerais & 15 & Sudeste \\
\hline 6 & Santa Catarina & 12 & Sul \\
\hline 7 & Ceará & 11 & Nordeste \\
\hline 8 & Paraná & 11 & Sul \\
\hline 9 & Sergipe & 10 & Nordeste \\
\hline 10 & Brasília (DF) & 9 & Centro-Oeste \\
\hline 11 & Espírito Santo & 9 & Sudeste \\
\hline 12 & Maranhão & 8 & Nordeste \\
\hline 13 & Pernambuco & 8 & Nordeste \\
\hline 14 & Mato Grosso do Sul & 6 & Centro-oeste \\
\hline 15 & Alagoas & 5 & Nordeste \\
\hline 16 & Bahia & 5 & Nordeste \\
\hline 17 & Goiás & 4 & Centro-oeste \\
\hline 18 & Roraima & 4 & Norte \\
\hline 19 & Tocantins & 4 & Centro-Oeste \\
\hline 20 & Amazonas & 3 & Norte \\
\hline 21 & Paraíba & 3 & Nordeste \\
\hline 22 & Pará & 2 & Norte \\
\hline 23 & Rondônia & Nenhuma & Norte \\
\hline
\end{tabular}

A apresentação desses dados propicia a visualização da concentração não apenas da Ginástica no país, como também da localização da região do Brasil onde há deficiência na sua promoção, desenvolvimento e/ ou organização. Ainda é possível verificar que, dentre as 240 entidades federadas em Ginástica no Brasil até o primeiro semestre de 2011, aproximadamente $60 \%$ concentravam-se nas regiōes Sudeste ( $40 \%$ das entidades filiadas/média de 24 por Estado) e Sul (18,33\%/média de 14 por Estado). Atualmente a região Nordeste tem uma boa representatividade, com $25 \%$ de entidades filiadas, porém ao se dividir este montante pelo número de Estados, chega-se a 7,5 entidades por Estado. Na regiāo Centro-Oeste serão sete entidades por Estado e, na região Norte, a de menor representatividade, 2,25 entidades por Estado.

Certamente essas concentrações são fruto de inúmeros fatores, dentre os quais os de ordem histórica e cultural da prática da Ginástica, mencionados anteriormente. Além disso, o início de sua prática institucionalizada ocorreu na região Sul e as primeiras Federações no país foram fundadas na região Sudeste (RS, SP e RJ), fatos que colaboraram para o desenvolvimento privilegiado da ginástica nessas regiōes. É importante considerar, também, a organização política esportiva das Federações Estaduais e da CBG para mudar, ou não, este quadro, pois após 33 anos da fundação desse órgão esportivo no país, e 69 anos da primeira Federação Estadual, ainda há Estados sem federaçōes, federações sem afiliados e uma centralização da ginástica nas mesmas regiōes de sua origem no Brasil. Para exemplificar o papel que a CBG poderia desempenhar na descentralização e incentivo para motivar a prática da ginástica em outras regiōes do país, a Federação Sergipana de Ginástica, que não constava dos dados coletados em 2007 no site da entidade ${ }^{11}$, atualmente tem 10 filiados e faz parte do quadro das 23 federaçôes de ginástica do Brasil.

Desde 2009 a Confederação Brasileira de Ginástica instalou-se em Aracajú/Sergipe e como é possível observar, mobilizou a sociedade local, inclusive com a instalação na cidade do centro de treinamento da seleção brasileira de Ginástica Rítmica. 
Nota-se, a partir dos dados apresentados, que ainda há muito a ser feito para o desenvolvimento das modalidades ginásticas já citadas, e que é fundamental um planejamento estratégico para que ocorram modificações.

Esta discussão mais ampla sobre a ginástica brasileira ou, mais precisamente, sobre as modalidades ginásticas organizadas pela CBG, justifica-se pelo fato da GAF estar inserida neste contexto maior, além de ser bastante difícil a análise por modalidade ginástica em cada Federação Estadual.

A discussão específica sobre a GAF é complementada, no decorrer do artigo, especialmente no subitem "A realidade da GAF em eventos nacionais".

\section{A ginástica artística feminina brasileira no cenário internacional}

O Sistema de Preparação Esportiva das ginastas nacionais de GAF sofreu grandes modificações, principalmente nos últimos 10 anos, devido especialmente ao investimento feito em equipamentos e contratação de treinadores ucranianos. No entanto, outras geraçôes de ginastas e técnicos, que não tiveram tanta repercussão na mídia como a geração atual, também contribuíram para o aperfeiçoamento desse Sistema.
As ginastas da atualidade dispõem de uma infraestrutura diferenciada: ginásios, aparelhos, apoio técnico e financeiro e equipe multidisciplinar nas áreas de nutrição, psicologia, fisioterapia, medicina, entre outras. Os efeitos desse suporte amplo, proporcionado ao Sistema de Preparação Esportiva, foram o crescimento dos resultados absolutos da seleção brasileira, nos JO de 2004 e 2008, em que os atletas da GAF alcançaram os melhores desempenhos até então, o que pode ser visualizado no QUADRO 2 a seguir:

QUADRO 2 - Evolução da participação brasileira em Campeonatos Mundiais de Ginástica Artística Feminina (1966-2011).

\begin{tabular}{|c|c|c|c|c|}
\hline $\mathrm{CM}$ (ano) & $\begin{array}{c}\text { País Campeão } \\
\text { na Classificaçáo por Equipes }\end{array}$ & Classificação da Equipe Brasileira & Melhor Brasileira Classificada & \multirow{23}{*}{$\begin{array}{l}\text { Fonte: Atualizado de } \\
\text { ScHIAVON }{ }^{12} \text {. }\end{array}$} \\
\hline 1966 & Tchecoslováquia & -.-.--- & Marion Faedrich Dullius - $148^{\circ}$ & \\
\hline 1970 & URSS & --.---- & --.--- & \\
\hline 1974 & URSS & ------- & Gisele Radomsky - $108^{\circ}$ & \\
\hline 1978 & URSS & $19^{\circ}$ & Lílian Carrascozza - 76º & \\
\hline 1979 & Romênia & $21^{\circ}$ & Claudia Magalhães - $108^{\circ}$ & \\
\hline 1981 & URSS & $19^{\circ}$ & Altair Prado - $80^{\circ}$ & \\
\hline 1983 & URSS & $22^{\circ}$ & Tatiana Figueiredo - 910 & \\
\hline 1985 & URSS & $20^{\circ}$ & Tatiana Figueiredo - $66^{\circ}$ & \\
\hline 1987 & Romênia & & Luisa Parente - $82^{\circ}$ & \\
\hline 1989 & URSS & $22^{\circ}$ & Margareth Yada - $106^{\circ}$ & \\
\hline 1991 & URSS & $28^{\circ}$ & Luisa Parente - sem registro da colocação & \\
\hline 1994 & Romênia & ------- & --.---- & \\
\hline 1995 & Romênia & $21^{\circ}$ & Soraya Carvalho $-37^{\circ}$ & \\
\hline 1997 & Romênia & --.----- & --.----- & \\
\hline 1999 & Romênia & -.---.-- & Daniele Hypólito - 270 & \\
\hline 2001 & Romênia & $11^{\circ}$ & Daniele Hypólito - $4^{\circ}$ & \\
\hline 2003 & EUA & $8^{\circ}$ & Camila Comin - $19^{\circ}$ & \\
\hline 2006 & China & $7^{\circ}$ & Daniele Hypólito - 21을 & \\
\hline 2007 & EUA & $5^{\circ}$ & Jade Barbosa - $3^{\circ}$ & \\
\hline 2009 & -------- (não houve CIV) & ------- & Bruna Leal - $14^{\circ}$ & \\
\hline 2010 & Rússia & $10^{\circ}$ & Jade Barbosa - 15ㅇ & \\
\hline 2011 & EUA & $14^{\circ}$ & Daniele Hypólito - 13o & \\
\hline
\end{tabular}


É possível perceber que em 45 anos, desde a primeira participação do Brasil em CM até a melhor classificação brasileira em 2007, houve uma evolução de 145 colocações, partindo da $148^{a}$ posição em 1966 para alcançar o $3^{\circ}$ lugar individual geral em 2007. Em termos de representatividade da equipe brasileira, nos primeiros 20 anos as classificações oscilam entre a $19^{a}$ e $28^{a}$ posições, e na última década colocam o Brasil entre as 10 melhores equipes do mundo. E, finalmente 39 anos após a primeira participação de equipe em
$\mathrm{CM}$, o Brasil classifica-se em $5^{\circ}$ lugar entre as nações de tradição na modalidade: URSS (oito vezes campeã mundial), Romênia (sete vezes campeã mundial), EUA (duas vezes campeã mundial), China (uma vez campeã mundial) e Rússia (uma vez campeã mundial).

A classificação do Brasil em JO parece similar à sua evolução em CM, mas com menor expressão, pois as potências mundiais na modalidade priorizam suas classificações em JO, como é possível verificar no QUADRO 3 a seguir:

QUADRO 3 - Evolução do Brasil perante outros países na Ginástica Artística Feminina em Jogos Olímpicos (1980-2012).

Fonte: Atualizado de SCHIAVON ${ }^{12}$.

\begin{tabular}{|c|c|c|c|}
\hline Jogos Olímpicos & Países campeóes por Equipes & Classificaçáo da Equipe Brasileira & Melhor Brasileira Classificada \\
\hline 1980 & $\begin{array}{l}1^{\circ}: \text { URSS } \\
2^{\circ}: \text { Romênia } \\
3^{\circ}: \text { Alemanha Oriental }\end{array}$ & --------- & $\begin{array}{c}31^{\circ} \\
\text { Boicote político }\end{array}$ \\
\hline 1984 & $\begin{array}{l}1^{\circ}: \text { Romênia } \\
2^{\circ}: \text { EUA } \\
3^{\circ}: \text { China }\end{array}$ & --.------ & $\begin{array}{c}27^{\circ} \\
\text { Boicote político }\end{array}$ \\
\hline 1988 & $\begin{array}{l}1^{\circ}: \text { URSS } \\
2^{\circ}: \text { Romênia } \\
3^{\circ}: \text { Alemanha Oriental }\end{array}$ & --------- & $34^{\circ}$ \\
\hline 1992 & $\begin{array}{l}\text { 10: CEI (ex-URSS) } \\
2^{\circ}: \text { Romênia } \\
\text { 3o: EUA }\end{array}$ & --.----- & $57^{\circ}$ \\
\hline 1996 & $\begin{array}{l}1^{\circ}: \text { EUA } \\
2^{\circ}: \text { Rússia } \\
3^{\circ}: \text { Romênia }\end{array}$ & -_-.--.--- & -------- \\
\hline 2000 & $\begin{array}{l}1^{\circ}: \text { Romênia } \\
2^{\circ}: \text { Rússia } \\
3^{\circ}: \text { China }\end{array}$ & --.----.-- & $20^{\circ}$ \\
\hline 2004 & $\begin{array}{l}1^{\circ}: \text { Romênia } \\
2^{\circ}: \text { EUA } \\
3^{\circ}: \text { Rússia }\end{array}$ & $9^{\circ}$ & $12^{\circ}$ \\
\hline 2008 & $\begin{array}{l}1^{\circ}: \text { China } \\
2^{\circ}: \text { EUA } \\
3^{\circ}: \text { Romênia }\end{array}$ & $8^{\circ}$ & $10^{\circ}$ \\
\hline 2012 & $\begin{array}{l}1^{\circ}: \text { EUA } \\
2^{\circ}: \text { Rússia } \\
3^{\circ}: \text { Romênia }\end{array}$ & $12^{\circ}$ & $36^{\circ}$ \\
\hline
\end{tabular}

Nos JO a nação de maior tradição na GAF foi a URSS, que venceu todos os JO desde o início das provas femininas, exceto nos JO de 1984, do qual não participou em função do boicote político aos Estados Unidos. A hegemonia da URSS foi retomada a partir dos JO de 1988 e nos JO de 1992 as ginastas soviéticas vencem, embora não representem mais a URSS e, sim, a Comunidade dos Estados Independentes. Após a abertura da URSS, um dos países, a Rússia, mantém-se ainda como destaque nas competiçōes, e conquista a medalha de ouro no CM de 2010. De 1952 até o ano 2000, 72 ginastas soviéticos participaram de JO e, destes, 49 foram campeões, alguns mais de uma vez. A ginástica soviética, posteriormente somada à ginástica russa, ganhou até o ano 2000, 89 medalhas de ouro olímpicas ( 45 no masculino e 44 no feminino) e, se forem somadas as medalhas de prata e bronze, o total do período é de 208 medalhas olímpicas. Em CM, os ginastas russos conseguiram um total de 133 medalhas de ouro ( 67 masculino e 66 feminino $)^{13}$.

A Romênia é outro país que sempre apresentou ginastas de destaque e participou com expressão dos pódios dos JO. Mais recentemente, nos últimos 20 anos, os Estados Unidos e a China juntaram-se às naçôes de destaque na ginástica feminina.

Como é possível observar no QUADRO 3, o Brasil participa dos JO na modalidade de GAF desde $1980 \mathrm{e}$, 
durante 20 anos, foi representado apenas por ginastas avulsas que se classificaram por nível técnico individual nos CM Pré-olímpicos. Essas ginastas destacaram-se por diversos fatores, mas é possível ressaltar que o intercâmbio técnico com profissionais de outras naçōes campeãs na modalidade teve um importante papel no processo de classificação para os JO.
Somente em 2003, no CM Pré-olímpico para Atenas, o Brasil conquistou a classificação inédita de uma equipe completa, ou seja, obteve a $8^{\text {a }}$ posição entre as 12 melhores nações classificadas, o que lhe garantiu o direito de participar com uma equipe nos JO.

As classificações e representações femininas do Brasil em JO encontram-se no QUADRO 4:

QUADRO 4 - Representações e classificações do Brasil na Ginástica Artística Feminina em Jogos Olímpicos $(1980-2012)^{d}$.

\begin{tabular}{|c|c|c|}
\hline Ano & Ginasta & Classificaçáo \\
\hline 1980 & Cláudia Magalhães (RJ): & $31^{\circ}$ \\
\hline 1984 & Tatiana Figueiredo (RJ): & $27^{\circ}$ \\
\hline 1988 & Luisa Parente (RJ): & $34^{\circ}$ \\
\hline 1992 & Luisa Parente (RJ): & $57^{\circ}$ \\
\hline 1996 & Soraya Carvalho (DF/defendia RJ): & Impossibilitada de participar devido a uma lesão \\
\hline \multirow[t]{2}{*}{2000} & Daniele Hypólito (SP/defendia RJ) & $20^{\circ}$ \\
\hline & Camila Comin (SP/defendia PR): & ------------- \\
\hline \multirow[t]{6}{*}{2004} & Daniele Hypólito (SP/defendia RJ) & $12^{\circ}$ (individual geral) \\
\hline & Daiane dos Santos (RS) & $5^{\circ}$ (prova de solo) \\
\hline & Camila Comin (SP/defendia PR) & $16^{\circ}$ (individual geral) \\
\hline & Caroline Molinari (PR), & $98^{\circ}$ \\
\hline & Ana Paula Rodrigues (PR) & $27^{\circ}$ \\
\hline & Laís Souza (SP/defendia PR) & $34^{\circ}$ \\
\hline \multirow[t]{6}{*}{2008} & Daiane dos Santos (RS/defendia SP) & $6^{\circ}$ (prova de solo) \\
\hline & Ana Cláudia Silva (RN/defendia PR) & $22^{\circ}$ (individual geral) \\
\hline & Jade Barbosa (RJ) & $\begin{array}{l}8^{\circ} \text { (individual geral) } \\
\left.7^{\circ} \text { (prova de salto }\right)\end{array}$ \\
\hline & Laís Souza (SP) & -_-_-_-.--.--- \\
\hline & Ethiene Franco (PR) & -..--..-- \\
\hline & Daniele Hypólito (SP/defendia RJ) & -.-.-.-.-.-.-. \\
\hline \multirow[t]{5}{*}{2012} & Bruna Leal (SP/defendia RJ) & $36^{\circ}$ \\
\hline & Daniele Hypólito (SP/defendia RJ) & $37^{\circ}$ \\
\hline & Ethiene Franco (PR) & $38^{\circ}$ \\
\hline & Daiane dos Santos (RS/defendia SP) & -.-.--.-.-.-.- \\
\hline & Harumi de Freitas (PR) & 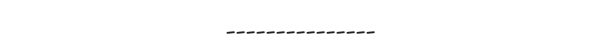 \\
\hline
\end{tabular}

---- = Não obteve classificação na competição "Individual Geral".
Em CM, a ginasta Daniele Hypólito, sob a orientação de Georgette Vidor (Clube de Regatas do Flamengo - RJ), conquista a primeira medalha para o país em 2001, com o segundo lugar na prova de Solo, fato inédito para a ginástica brasileira e, na mesma competição, classifica-se em $4^{\circ}$ lugar no individual geral.

No ano de 2003 o Brasil demonstrou grande evolução técnica no CM Pré-olímpico (EUA), e classificou a equipe na $8^{a}$ posição, conforme citado anteriormente.

No mesmo CM a ginasta Daiane dos Santos apresentou um novo exercício na prova de solog , o "duplo twist carpado", que recebeu seu sobrenome:
DOS SANTOS, e ainda conquistou a medalha de ouro nesta prova. Na época, a ginasta era orientada por Adriana Alves (Grêmio Náutico União - RS), assessorada pela equipe de ucranianos no Brasil.

A ginasta Jade Barbosa conquistou a medalha de bronze na classificação individual geral do CM Pré-olímpico na Alemanha em 2007 e participou de duas finais por aparelho: Salto e Trave de Equilíbrio. No CM na Holanda, em 2010, a ginasta conquistou mais uma medalha de bronze na prova de Salto.

Essa evolução da GA brasileira, não somente no número de ginastas participantes de $\mathrm{JO}$, mas 
na qualidade das classificações, foi influenciada também pela tradição e competência de técnicos europeus, de Cuba, dos Estados Unidos (EUA) e, principalmente, dos países da antiga URSS. O impacto é fruto de intercâmbios com os clubes brasileiros, que contribuíram para o crescimento da GAF no país, principalmente com a qualificação de técnicos brasileiros.

Durante dois ciclos olímpicos, até 2008, a comissão técnica brasileira foi formada por três técnicos ucranianos: Oleg Ostapenko, Iryna Ilyashenko e Nadia Ostapenko. A CBG os trouxe, com o apoio do Comitê Olímpico Brasileiro e do Comitê Olímpico Internacional, para trabalharem diretamente com a seleção brasileira, como NunOMURA e Oliveira ${ }^{14}$ revelam: [...] os honorários da comissão técnica formada por treinadores brasileiros e estrangeiros, a manutenção das atletas e o pagamento da equipe multidisciplinar para oferecer suporteà equipe foram subsidiados com recursos da Lei Agnelo/Piva e do patrocinador oficial da CBG (OLIVEIRA, 2010). Além desse apoio, a CBG dispunha de recursos do Programa Solidariedade Olímpica do Comitê Olímpico Internacional (COI) que, de acordo com o COB (2006b), custeou os salários do técnico chefe durante o período da sua permanência no Brasil (p.80-1).

Este trabalho foi iniciado no ano de 1999 com a chegada da primeira técnica ucraniana e teve como foco principal os JO de 2008. Este período de trabalho no Brasil propiciou uma impressionante repercussão nacional e internacional para a GA brasileira.

Apesar dessa ascensão nítida de classificações, é importante destacar que o Brasil, na GAF, ainda tem poucos resultados internacionais de real êxito, ou seja, medalhas em CM e JO. A perspectiva é de que esse quadro se modifique, caso a evolução continue no mesmo ritmo da última década. As medalhas que o país obteve na GAF são: uma de ouro, uma de prata e duas de bronze em CM 2001, 2003, 2007 e 2010. No entanto, ainda há muito por fazer para sedimentar esta conquista, como pode ser visto a seguir.

\section{A realidade da GAF em eventos nacionais}

Ao apresentar um breve panorama da modalidade no Brasil, desde sua origem, assim como a evolução das ginastas brasileiras no cenário internacional, cabe neste momento uma análise mais profunda acerca de uma realidade com dados preocupantes, que sinalizam como o esporte está se desenvolvendo, assim como quais poderiam ser suas perspectivas de crescimento e estruturação.

Um olhar cuidadoso sobre a realidade dos Campeonatos Brasileiros da GAF, revela que o número de participantes e entidades é reduzido e, em sua maioria, restritos às regiōes Sul e Sudeste.

Além da baixa frequência de participantes de outras regiōes do país, é possível observar que justamente no período de maior crescimento de classificações da seleção brasileira de GAF internacionalmente não houve um aumento no número de participantes em Campeonatos Brasileiros. No período de 2005 a 2008, não houve mais do que 15 ginastas adultas em nível competitivo ${ }^{12}$.

O fato dos Campeonatos Brasileiros de 2003 a 2009 contemplarem praticamente os clubes da região Sul e Sudeste ${ }^{15}$, pode estar associado às deficiências na estrutura técnica e material. Isso compromete o desenvolvimento da ginástica de outras regiōes do país, com participações esporádicas de ginastas avulsas em Campeonatos Brasileiros, como: uma ginasta pré-infantil (RN) e três infantis (DF), em 2004, e uma infantil (PA) em 2006 ${ }^{15}$. Estes fatos corroboram a discussão anterior de que a concentração de número de filiados nas regiōes Sul e Sudeste, das modalidades ginásticas de forma geral, condiz com o quadro atual da GAF, que também se concentra nessas regiōes.

PúBliO ${ }^{3}$ menciona que, entre os anos de 1980 a 1995, não houve mais do que cinco equipes completas participando de Campeonatos Brasileiros da categoria adulta, e apenas duas das ediçôes tiveram equipes de Federações de outros Estados que não fossem da região Sudeste. Estes dados contrastam com o fato da Rússia ter representantes de 32 diferentes cidades na seleção nacional ${ }^{13}$, indicativos de que a competência profissional e a estrutura material estão disseminadas naquele país.

No QUADRO 5, é possível observar a estabilidade no número de ginastas e equipes (compostas por um número mínimo de três e máximo de seis ginastas) participantes de Campeonatos Brasileiros de 2004 a 2008: 
QUADRO 5 - Número de participantes de Campeonatos Brasileiros de Ginástica Artística Feminina.

\begin{tabular}{|clcccc|}
\hline Ano & \multicolumn{1}{c}{ Adulto } & Juvenil (Equipes/Ginastas) & Infantil A & Pré-infantil A & Pré-infantil B \\
\hline 2004 & $\begin{array}{l}31 \text { ginastas } \\
(20 \text { adultas) }\end{array}$ & $3 / 17$ & $4 / 31$ & $3 / 22$ & $5 / 26$ \\
2005 & $\begin{array}{l}4 \text { equipes } \\
21 \text { ginastas (10) }\end{array}$ & ------ & ----- & $2 / 14$ & $4 / 20$ \\
2006 & $\begin{array}{l}23 \text { ginastas (12) } \\
6 \text { equipes } \\
28 \text { ginastas (15) } \\
5 \text { equipes } \\
33 \text { ginastas (13) }\end{array}$ & $7 / 41$ & $5 / 25$ & $6 / 31$ & $6 / 23$ \\
2008 & $5 / 31$ & $6 / 38$ & $6 / 28$ & $9 / 42$ \\
\hline
\end{tabular}

No que tange ao número de ginastas de alto rendimento esportivo, o Brasil apresenta-se distante de países de destaque internacional, como Romênia, Rússia e Estados Unidos que, apresentam uma relação historicamente construída com a modalidade e desenvolvem uma política esportiva desde as categorias de base. Nesses países, o grande enfoque é direcionado ao processo de qualificação de técnicos, sendo que os efeitos dessa iniciativa são identificados no grande número de ginastas que competem em todos os níveis das categorias de base. Isso possibilita a cada um desses países compor uma seleção nacional mais competitiva e com elevado nível técnico para representá-los em JO e CM.

No ano de 2008, a Federação Norte Americana de Ginástica informou ${ }^{f}$ que no país competem 20 a 24 ginastas adultas, consideradas de alto rendimento esportivo, denominadas "nível de elite". Além disso, mais 20 a 24 ginastas competem na categoria júnior, também "nível de elite", e representam o país internacionalmente. Adicionalmente, outras 400 ginastas participam do Campeonato Nacional Júnior. $\mathrm{Na}$ Rússia, no ano 2000, aproximadamente 61.600 crianças praticavam GA, sendo 30.500 em grupos de iniciação esportiva, 16.000 em grupos de treinamento, 854 em grupos avançados e 174 na elite da modalidade ${ }^{13}$. Estes números contrastam com os de participação de ginastas adultas no Campeonato Brasileiro, entre os anos de 2004 a 2008, cuja média por campeonato foi de 14 atletas $^{12}$.

O número reduzido de ginastas competitivas no Brasil ao longo de vários anos pode ser reflexo de diversos fatores. Dentre eles, três podem ser considerados fundamentais: a insuficiência de técnicos com qualificação adequada, a precariedade de espaços públicos e privados adequados para o treinamento das equipes, e a irregularidade e/ou insuficiência de políticas públicas que invistam no esporte de base e de rendimento.
Com relação à insuficiência de técnicos com qualificação adequada, este parece ser um problema oriundo da própria construção histórica da modalidade no país, e que precisa urgentemente ser revisitada e aprimorada. É necessária a criação de um sistema estruturado para a formação de técnicos, para que estejam melhor preparados para formar ginastas, e esse preparo deve se estender tanto às categorias de base dos campeonatos brasileiros, que não necessitam de alta condição de infraestrutura, quanto às categorias juvenil e adulta que, pela exigência técnica de alta complexidade e risco dos exercícios realizados, requerem uma melhor infraestrutura. Esta observação é corroborada por Nunomura e Oliveira ${ }^{14}$ ao pesquisarem a opinião dos técnicos brasileiros sobre o Centro de Treinamento permanente que preparou a GAF brasileira para os JO de 2004 e 2008 no Brasil:

Os técnicos afirmam que não ocorreu um processo contínuo de cursos organizados pela CBG que pudessem promover a formação dos técnicos nacionais. Apenas os técnicos que trabalhavam no CT em Curitiba puderam aprender com os treinadores estrangeiros que, de acordo com $\mathrm{T} 9$, realizaram apenas um curso no ano de 1999. Na visão de T16B, "tecnicamente deveriam criar oportunidades para os técnicos nacionais desenvolverem-se". Nunomura (2004) afirma que os técnicos possuem a necessidade de uma formação continuada, pois, à medida que os seus ginastas evoluem eles precisam ampliar o seu conhecimento e o oferecimento de cursos específicos permitiria que estes profissionais prosseguissem e se aprimorassem na carreira (p.387).

Em sua tese de doutorado, NunOmURA ${ }^{16}$, que abordou a formação do técnico de GA, sugere a exigência de uma certificação, a exemplo do que ocorre em outros países, e refere-se também à falta de qualificação deste profissional no Brasil:

Diante dos problemas enfrentados com a formação de profissionais não houve, até o momento, nenhuma 
iniciativa por parte da Confederação ou das Federaçôes de Ginástica em se criar cursos para formação dos nossos técnicos. Parte desta responsabilidade também compete a estes órgãos, que devem primar pela qualidade dos serviços prestados neste setor.

A vinda de técnicos de várias partes do mundo também não resolveu o problema, uma vez que não houve uma intenção de se disseminar o conhecimento e a experiência desses técnicos, ficando restrito apenas àquelas instituiçôes que puderam custear a sua estada no país (p.45).

Merece ainda destaque a necessidade de um maior investimento no ensino da ginástica nos cursos de graduação em Educação Física e Ciências do Esporte, considerando-se que, em alguns destes cursos, a ginástica não faz parte do currículo, ou somente são abordados aspectos relacionados ao condicionamento físico ou ao ensino dos elementos básicos da modalidade, conforme apontam os estudos de BARBOSA-Rinaldi e SouZA ${ }^{17}$.

Com relação à precariedade de espaços públicos e privados adequados para o treinamento das equipes, nota-se também uma reclamação constante de técnicos (dos diferentes níveis e categorias), acerca deste tema.

Conforme apontado por SCHIAVON e PAES ${ }^{18}$ :

No Brasil, as instituiçóes desportivas que organizam

a GA nos Estados e nacionalmente não têm demonstrado e realizado um efetivo sistema que organize e coordene a atuação dos técnicos, ou ofereça condiçôes mínimas de infraestrutura para a prática da modalidade em diferentes regiōes do país (p.759).

A mesma publicação ainda apresenta dados de condiçôes de infraestrutura de ginastas brasileiras participantes de Jogos Olímpicos, no período de
1980 a 2004, e revela que todas as ginastas em algum momento de suas carreiras esportivas passaram por condições inadequadas de treinamento. Soma-se a isso a existência de poucos centros de treinamento de GA nas diferentes regiōes do país, e até mesmo nos Estados das regiôes Sul e Sudeste onde, conforme os dados apresentados, há uma concentração da prática da modalidade. Segundo os sites oficiais da Confederação Brasileira de Ginástica e da organização dos Jogos Olímpicos, a RIO2016, os únicos dois Centros de Treinamento para a Ginástica Artística são o da Secretaria de Esporte do Estado do Paraná, em Curitiba e o Centro de Treinamento "Time Brasil", inaugurado em 2012 no Rio de Janeiro ${ }^{19-20}$.

$\mathrm{O}$ terceiro fator fundamental refere-se à irregularidade e insuficiência de políticas públicas que invistam no esporte de base e de rendimento, nos níveis Municipal, Estadual e Federal. Segundo PINTO ${ }^{21}$, há uma descontinuidade dos programas públicos de esporte e lazer, principalmente devido a fatores de ordem político partidária (articulados durante e após as campanhas eleitorais); uma não valorização do esporte na política pública de maneira mais ampla pois não há uma concepção do esporte voltada para as questões culturais, educacionais, artísticas, políticas etc. Da mesma forma há escassez de projetos intersetoriais, estabelecendo diálogos e ações entre o setor esportivo e os demais setores públicos.

Estes fatores por nós considerados como fundamentais, dentre outros, como a tímida apropriação e aplicação dos resultados das pesquisas científicas para a formação de técnicos e evolução das ginastas, colaboram para uma estabilização e, em alguns momentos, uma desaceleração ou redução na formação de ginastas.

\section{Discussão}

A apresentação e discussão dos dados das Federações, CBG, JO, CM e campeonatos nacionais permitiram visualizar um panorama da GAF brasileira e estimular reflexões sobre seus avanços e necessidades.

Durante os 28 anos de participações brasileiras em JO, algumas questões ficam mais nítidas, como a evolução técnica das ginastas e dos resultados da GAF brasileira no contexto internacional. Essa evolução foi exposta no presente artigo por meio de dados mais concretos e específicos (advindos de diferentes métodos de pesquisa), que permitiram uma análise mais plural e densa deste fenômeno, e colaborou, inclusive, para dismitificar matérias exibidas pelos meios de comunicação, que retratam a GAF brasileira como uma modalidade bem estruturada e consolidada. $O$ fato de a GAF ter conquistado, nos últimos 10 anos, posições de destaque no cenário internacional, não reflete, neste caso, um sistema bem organizado de desenvolvimento da modalidade no país.

Além disso, há também claras dificuldades e entraves relacionados à GA brasileira nas diversas regiōes do Brasil, que não retratam e nem se aproximam da organização e do apoio oferecido à seleção brasileira de GAF, até os JO de 2008.

Os problemas apresentados levam à restrição de desenvolvimento da modalidade nas regiōes (Sul e 
Sudeste) e sua tímida expressão nas demais regiōes, que ficam evidentes quando se expõem os dados do Brasil como um todo.

Após 34 anos de fundação da CBG, os Estados das regiōes brasileiras Sul e Sudeste ainda permanecem, não apenas como destaque, mas como únicos participantes, na maioria das vezes, dos campeonatos nacionais, como já mencionado anteriormente.

GRIGORYANTS $^{22}$ ao expor os problemas atuais na ginástica russa relata que as regiōes da Rússia foram completamente esquecidas, depois que se concentrou todos os ginastas no mesmo local e sob os olhos de uma mesma pessoa. Além disso, o autor aponta que é necessário começar a promover a ginástica nas pequenas cidades, e que os técnicos tenham autonomia para desenvolver seu próprio trabalho.

Situação similar ocorre no Brasil com a concentração, na última década, das ginastas em Curitiba. O conhecimento ficou centralizado e privilegiou os profissionais do Centro de Excelência, circunstância que contribuiu para a não expansão da ginástica para outras regiōes do país. NunOMURA e OliveIrA ${ }^{14}$ ao pesquisarem técnicos brasileiros sobre o Centro de Treinamento em Curitiba discutem:

Segundo alguns técnicos, os treinadores nacionais não tiveram oportunidade de demonstrar o seu potencial, pois jamais tiveram à disposição uma infraestrutura semelhante à que a $\mathrm{CBG}$ proporcionou aos técnicos estrangeiros. Muitos acreditam que a entidade deveria ter oferecido aos técnicos brasileiros a possibilidade de aperfeiçoamento profissional aproveitando a estada dos técnicos estrangeiros. Eles afirmam que estavam muito interessados em aprender e se aprimorar, mas não perceberam iniciativas da CBG (p.389-90).

Outra questão a ser destacada é a proximidade entre o número de ginastas da categoria adulta de alto rendimento esportivo e o número de ginastas necessário para compor a seleção brasileira. $\mathrm{Ou}$ seja, não há ginastas reservas do mesmo nível técnico, e não restam muitas opções para os técnicos na definição das seleçôes representativas do país. Assim, fica claro que não há renovação suficiente, com a permanência das mesmas ginastas na seleção brasileira durante vários ciclos olímpicos. No Brasil, no ano de 2008, 146 ginastas participaram de campeonatos nacionais, somando-se todas as categorias (pré-infantil, infantil, juvenil e adulto), o que representa $36,5 \%$ de apenas uma categoria de ginastas norte-americanas ${ }^{\mathrm{g}}$ citadas anteriormente $^{12}$.

Foi identificada também a necessidade de uma melhor estruturação para a capacitação dos técnicos, desde a formação profissional (nos cursos de graduação) até a formação continuada, que pode ser propiciada pela proposta de um plano de capacitação pela CBG (dado que esta é uma de suas missões) e também por parceria com a Universidade. É importante destacar a iniciativa do Comitê Olímpico Brasileiro, em conjunto com diferentes universidades brasileiras, que iniciou, em 2012, um programa de capacitação para técnicos de alto rendimento esportivo em Ginástica Artística ${ }^{23}$, por meio da Academia Brasileira de Treinadores.

Ainda em relação a esta questão, faz-se também necessário refletir que a importação de técnicos estrangeiros deve ser melhor gerenciada e aproveitada, pois "importar técnicos resolve o problema momentâneo e particular da instituição, porque eles não estão preparados para trabalhar na formação de novos técnicos" (p.153) ${ }^{16}$. Além disso, muitas vezes não estão abertos a novas experiências e adaptações de seus trabalhos para outras culturas.

Há vários estudos finalizados e outros em andamento nas universidades brasileiras, sobre o desenvolvimento da GA de base ${ }^{24-29}$, sobre a certificação de cursos de qualificação técnica ${ }^{16}$, entre outros assuntos, que já foram discutidos, pensados, confrontados com outros países e que não tiveram a oportunidade de serem concretizados, devido à centralização política das decisões que envolvem a GA de alto rendimento.

Há também a falta de comunicação efetiva entre o que é produzido nas universidades e o técnico de GA, pois muitas vezes a Universidade não cria mecanismos para tornar as pesquisas viáveis para o consumo, e nem os técnicos procuram as universidades para se atualizar e compartilhar experiências e saberes. $\mathrm{O}$ distanciamento das federaçôes estaduais e da CBG, e destas com as universidades, não favorece o crescimento da ginástica brasileira. E ademais, em muitos casos, não se permite aos pesquisadores desenvolverem seus projetos em parceria com os técnicos e junto às seleçôes. Sugere-se, portanto, o estreitamento das relaçôes entre os centros de pesquisa e as entidades esportivas, a fim de agregar iniciativas direcionadas ao aprimoramento da GA brasileira.

Para a continuidade desta evolução da GAF brasileira no âmbito internacional muitos fatores devem ser considerados, com destaque, entre outros, da qualidade dos treinamentos. Há a necessidade de se discutir a formação esportiva de ginastas, o que requer o entendimento de diferentes aspectos envolvidos neste processo, com destaque para o sistema de preparação esportiva e a organização da modalidade. O Brasil precisa ampliar a qualificação 
e o aprimoramento de técnicos de uma forma organizada e sistemática para os diversos níveis de GAF, ou seja, desde a iniciação até o alto rendimento esportivo. Algumas propostas nesta direção já foram, e estão sendo, debatidas embora ainda poucas tenham de fato se efetivado.

\title{
Notas
}

a. As coletas com os dirigentes foram realizadas por telefone, respaldadas por LAVILLE e DiOnE ${ }^{30}$, quando se referem às possibilidades da realização da entrevista como um instrumento de pesquisa, e consideram que "o trabalho pode ser feito por ocasião de um encontro entre entrevistador e entrevistado, mas será mais frequentemente realizado por telefone” (p.187). A partir deste levantamento, que faz parte da pesquisa documental, surgem os dados inéditos expostos no QUADRO 1 deste artigo (não anteriormente publicados).

b. Sentido que se pretende neste artigo do termo "evolução": "Desenvolvimento ou transformação gradual e progressiva" c. Modalidade ainda não era denominada desta forma, porém aqui usaremos o termo utilizado na atualidade, Ginástica Artística, e não ginástica olímpica como era chamada na época, para esclarecer melhor o leitor sobre o tipo de modalidade ginástica que se organizava no referido período.

d. O QUADRO 4 foi organizado a partir de dados dispersos disponíveis no site Federação Internacional de Ginástica ${ }^{32}$. e. Em resposta a e-mail, pois a informação não constava no site da Federação Norte-Americana de Ginástica.

f. As ginastas norte-americanas foram campeãs olímpicas “por equipes” nos Jogos Olímpicos de Londres (2012).

g. A primeira ginasta brasileira a apresentar um exercício novo para o código de pontuação e registrar o sobrenome no código de pontuação foi Heine Araújo, em 2002, com o exercício de saída de Trave de equilíbrio: Salto "fwd stretched with 2/1 twist $\left(720^{\circ}\right)$ -Take-off only from both legs" (Mortal para frente estendido com duplo giro - saída com impulsão em dois pés - tradução nossa) ${ }^{33}$.

\begin{abstract}
Overview of the high performance Brazilian women's artistic gymnastic: progression, reality and necessities

The Brazilian Women's Artistic Gymnastics results in international championships are reflecting the high level of the athletes in the modality and expressing the evolution of this sport in Brazil in the last 10 years. Therefore, this article has the goal to present data about such evolution since the first participation of the Brazilian gymnasts in the Olympic Games (1980), and to reflect the development of the modality in Brazil. The data have been collected through a bibliographic and documental research. The data analysis showed a unstructured and immature process of the development of this sport in Brazil, revealing a very different reality from what has been exposed in the media.
\end{abstract}

KEY WORDS: Gymnastics; Olympic Games; Sport.

\section{Referências}

1. Tesche L. O Turnen, a educação e a educação física nas escolas teuto-brasileiras no Rio Grande do Sul: 1852-1940. Ijuí: Unijuí; 2002.

2. Fiorin CMA. Ginástica em Campinas: suas formas de expressão da década de 20 a década de 70 [dissertação]. Campinas (SP): Universidade Estadual de Campinas, Faculdade de Educação Física; 2002.

3. Públio NS. Evolução histórica da ginástica olímpica. Guarulhos: Phorte; 1998.

4. Sagawa SM. Uma história do desenvolvimento da ginástica artística paulista [dissertação]. São Paulo (SP): Universidade São Judas Tadeu; 2011

5. Cantarino Filho M. A educação física no Estado Novo: história e doutrina [dissertação]. Brasília (DF): Universidade de Brasília; 1982. 
6. Marinho IP. História da educação física no Brasil. São Paulo: Brasil Editora; s.d.

7. Toledo E. Proposta de conteúdos para a ginástica escolar: um paralelo com a teoria de Coll [dissertação]. Campinas (SP): Universidade Estadual de Campinas, Faculdade de Educação Física; 1999.

8. Santos JCE, Publio NS, Alonso H, et al. Ginástica - Federação Internacional de Ginástica/FIG - Confederação Brasileira de Ginástica/CBG. In: DaCosta L, organizador. Atlas do esporte no Brasil. Rio de Janeiro: Shape; 2005.

9. Públio NS. Ginástica artística (GA). In: DaCosta L, organizador. Atlas do esporte no Brasil. Rio de Janeiro: Shape; 2005.

10. CBG. Confederação Brasileira de Ginástica. Estatuto. [citado 7 jul 2008]. Disponível em: http://cbginastica.com.br/ web/index.php?option=com_content\&task=view\&id=33\&Itemid=46.

11. CBG. Confederação Brasileira de Ginástica. Federações. [citado: 13 jun 2007]. Disponível em: http://www.cbginastica. com.br/web/.

12. Schiavon LM. Ginástica artística feminina e história oral: a formação desportiva de atletas brasileiras participantes de Jogos Olímpicos (1980-2004) [tese]. Campinas (SP): Universidade Estadual de Campinas, Faculdade de Educação Física; 2009.

13. Arkaev LI, Suchilin NG. Gymnastics: how to create champions. Oxford: Meyer \& Meyer Sport; 2004.

14. Nunomura M, Oliveira MS. Centro de excelência e ginástica artística feminina: a perspectiva dos técnicos brasileiros. Motriz, 2012;18:378-92.

15. CBG. Confederação Brasileira de Ginástica. Resultados. [citado 12 dez 2009]. Disponível em: http://www.cbginastica. com.br/web/.

16. Nunomura M. Técnico de ginástica artística: uma proposta para a formação profissional [tese]. Campinas (SP): Universidade Estadual de Campinas, Faculdade de Educação Física; 2001.

17. Barbosa-Rinaldi IP, Souza EPM. Saberes ginásticos necessários à formação profissional em educação física: encaminhamentos para uma estruturação curricular. Rev Bras Ciênc Esporte, 2008;29:227-43.

18. Schiavon LM, Paes RR. Condiçōes dos treinamentos de ginastas brasileiras participantes de jogos olímpicos (19802004). Motriz, 2012;18:757-69.

19. CBG. Confederação Brasileira de Ginástica. Notícias. [citado 20 abr. 2013]. Disponível em: http://cbginastica.com.br/ cbg/index.php?option=com_content\&view=article\&id=264:centro-de-treinamento-de-ginastica-artistica-e-inauguradono-rio-de-janeiro\&catid=1:latest-news \&Itemid $=50$.

20. RIO2016. Locais de treinamento pré-jogos. [citado 20 abr 2013]. Disponível em: http://www.rio2016.com/pregamestraining/pt/complexo-esportivo-da-secretaria-de-estado-do-esporteipce.

21. Pinto LMSM. Políticas públicas de lazer no Brasil: uma história a contar. In: Marcellino NC. Políticas públicas de lazer. Campinas: Alínea; 2008.

22. Grigoryants IA. Sport gymnastics: from Sydney to Athens. [citado 29 ago 2008]. Disponível em: http://Lib.sportedu. $\mathrm{ru} / \mathrm{press} / \mathrm{tpfk} / 2005 \mathrm{~N} 4 / \mathrm{p} 28-34 . \mathrm{htm}$.

23. COB. Comitê Olímpico Brasileiro. COB lança Academia Brasileira de Treinadores [citado 25 jul 2013]. Disponível em: http://www.cob.org.br/noticias-cob/cob-lana-academia-brasileira-treinadores-033496.

24. Nunomura M, Tsukamoto M. Fundamentos da ginástica artística. In: Nunomura M, Tsukamoto M, organizadores. Fundamentos das ginásticas. Jundiaí: Fontoura; 2009.

25. Toledo E. A ginástica rítmica e artística no ensino fundamental: uma prática possível e enriquecedora. In: Moreira, EC, organizador. Educação física escolar: desafios e propostas I. Jundiaí: Fontoura; 2009.

26. Nunomura M. Ginástica artística. São Paulo: Odysseus; 2008. (Coleção Agôn).

27. Schiavon LM, Nista-Piccolo VL. Desafios da ginástica na escola. In: Moreira EC, organizador. Educação física escolar: desafios e propostas II. Jundiaí: Fontoura; 2006.

28. Schiavon LM. Materiais alternativos para a ginástica artística. In: Nunomura M, Nista-Piccolo VL, organizadores. Compreendendo a ginástica artística. São Paulo: Phorte; 2005.

29. Nista-Piccolo VL. Pedagogia da ginástica artística. In: Nunomura M, Nista-Piccolo VL. Compreendendo a ginástica artística. São Paulo: Phorte; 2005.

30. Laville C, Dione J. A construção do saber: manual de metodologia de pesquisa em ciências humanas. Porto Alegre: Artes Médicas Sul; 1999.

31. Dicionário Priberam da Língua Portuguesa. Lisboa: Priberam Informática; 2012. Evolução. [citado 2 out 2012]. Disponível em: http://www.priberam.pt/dlpo/default.aspx?pal=evolu\%C3\%A7\%C3\%A3o.

32. FIG. Federação Internacional de Ginástica. Results. [citado 23 ago 2013]. Disponível em: http://www.fig-gymnastics. com/vsite/vnavsite/page/directory/0,10853,5187-188446-205668-nav-list,00.html.

33. Nunomura M. Ginástica artística. 2a ed. São Paulo: Odysseus; 2009. 
Schiavon LM, et al.

\section{Agradecimentos}

Agradecemos a pronta colaboração dos dirigentes, e de suas equipes, no fornecimento das informaçôes para esta pesquisa.

ENDEREÇO

Laurita Marconi Schiavon Universidade Estadual Paulista - Campus Rio Claro

Av. 24A, 1515

13506-900 - Rio Claro - SP - BRASIL

e-mail: laurita@rc.unesp.br
Recebido para publicação: 04/05/2012

Revisado: 26/04/2013

Aceito: 01/05/2013

436 • Rev Bras Educ Fís Esporte, (São Paulo) 2013 Jul-Set; 27(3):423-36 


\section{Errata do Autor}

\section{v.27, n.3, set./out. 2013}

\author{
No artigo "Panorama da ginástica artística \\ feminina brasileira de alto rendimento esportivo: \\ progressáo, realidade e necessidades", os autores, \\ Laurita Marconi Schiavon, Roberto Rodrigues Paes, \\ Eliana de Toledo e Silvia Deutsch fizeram uma \\ colocação equivocada.
}

No décimo segundo parágrafo, da A ginástica artística feminina brasileira, p.429:

No mesmo CM a ginasta Daiane dos Santos apresentou um novo exercício na prova de solo, o "duplo twist carpado", que recebeu seu sobrenome: DOS SANTOS, outro fato inédito para o Brasil e ainda conquistou a medalha de ouro nesta prova. $\mathrm{Na}$ época, a ginasta era orientada por Adriana Alves (Grêmio Náutico União - RS), assessorada pela equipe de ucranianos no Brasil.

\section{O correto é:}

No mesmo CM a ginasta Daiane dos Santos apresentou um novo exercício na prova de solog, o "duplo twist carpado", que recebeu seu sobrenome: DOS SANTOS, e ainda conquistou a medalha de ouro nesta prova. $\mathrm{Na}$ época, a ginasta era orientada por Adriana Alves (Grêmio Náutico União - RS), assessorada pela equipe de ucranianos no Brasil.

g. A primeira ginasta brasileira a apresentar um exercício novo para o código de pontuaçáo e registrar o sobrenome no código de pontuação foi Heine Araújo, em 2002, com o exercício de saída de Trave de equilíbrio: Salto "fwd stretched with $2 / 1$ twist $\left(720^{\circ}\right)$ - Take-off only from both legs" (Mortal para frente estendido com duplo giro - saída com impulsão em dois pés - tradução nossa) ${ }^{33}$.

33. Nunomura M. Ginástica artística. 2a ed. São Paulo: Odysseus; 2009. 